\title{
Efficacy and safety of apraclonidine in patients undergoing anterior segment laser surgery
}

\author{
B SRIDHARRAO AND S S BADRINATH \\ From the Vision Research Foundation, 18 College Road, Madras-600 006, India
}

\begin{abstract}
SUMmARY The efficacy of $1.0 \%$ apraclonidine (para-aminoclonidine) in preventing the rise of intraocular pressure following anterior segment, laser surgery was evaluated in a randomised double-masked study. Ninety-nine consecutive patients requiring laser treatment of the anterior segment were included in the study. They were randomised into two groups, one receiving $1.0 \%$ para-aminoclonidine and the other placebo (vehicle of para-aminoclonidine). The drug caused a statistically significant reduction in pressure after the laser treatment without causing clinically significant side effects such as bradycardia or hypotension.
\end{abstract}

During the past few years a number of investigators have reported that a transient intraocular pressure (IOP) rise may follow any anterior segment laser surgery such as argon laser trabeculoplasty, argon or YAG laser iridotomy, or YAG laser capsulotomy. ${ }^{1-h}$ This rise in IOP appears to be unrelated to the type of therapy, the type of laser used, the total amount of energy delivered, bleeding, or cellular debris that occurs during treatment, or to the degree of inflammation after treatment. The IOP rose despite the use of topical ocular hypotensive or non-steroidal anti-inflammatory agents. ${ }^{-{ }^{-}}$

A rise in pressure following laser procedures is at present being treated with carbonic anhydrase inhibitors, oral hyperosmotic agents, or topical timolol, each of which may have undesirable side effects. Apraclonidine is a topical derivative of clonidine prepared by Alcon Laboratories and has minimal systemic hypotensive effects." Animal studies have shown that apraclonidine ophthalmic solution produces minimal systemic pharmacotoxic effects.

This study, which is prospective, randomised, and controlled, analyses the efficacy of apraclonidine in preventing a rise in IOP in patients undergoing anterior segment laser procedures, namely, $\mathrm{Nd}$ YAG laser capsulotomy and argon Nd-YAG laser iridotomy.

Correspondence to Dr B S Rao.

\section{Patients and methods}

Ninety-nine consecutive patients who underwent anterior segment laser treatment between August 1987 and January 1988 at the Vision Research Foundation, Madras, India, were prospectively studied. The following criteria determined exclusion from participation in the study: (1) active ocular infection or inflammation; (2) any past or present severe ocular pathology apart from cataract and glaucoma; (3) unstable cardiovascular disease which may be adversely affected by an $\alpha$-adrenergic agonist, such as labile hypertension and history of stroke; (4) any abnormality preventing reliable applanation tonometry; (5) pregnant or nursing women and women of childbearing potential; (6) participation in any other investigational drug study within past 30 days; (7) patients with vision in one eye only; (8) patients taking systemic clonidine.

Approval for the study was obtained from the Ethics and Research Subcommittees of Vision Research Foundation, Madras, India. After informed consent had been obtained, at a prestudy examination a medical history was taken, ocular examination carried out, and heart rate and blood pressure recorded. The patients were then randomly assigned to either treatment $(1.0 \%$ apraclonidine $)$ or placebo groups (vehicle of apraclonidine). Only one eye of each patient was included in the study. Neither the patient nor the investigator was aware of the treat- 
Table 1 Age and sex groups: 1 (Apraclonidine) and 2 (placebo)

\begin{tabular}{|c|c|c|c|c|c|c|}
\hline \multirow[b]{2}{*}{ Age group } & \multicolumn{3}{|c|}{ Group I (Apraclonidine) } & \multicolumn{3}{|c|}{ Group 2 (placebo) } \\
\hline & Male & Female & Total & Male' & Female & Total \\
\hline$<20$ & - & - & - & - & - & - \\
\hline $20-40$ & 3 & 1 & 4 & 6 & 3 & 9 \\
\hline $41-60$ & 23 & 11 & 34 & 14 & 14 & 28 \\
\hline $61-70$ & 9 & 1 & 10 & 8 & 6 & 14 \\
\hline$>70$ & - & - & - & - & - & - \\
\hline Total patients & 35 & 13 & 48 & 28 & 23 & 51 \\
\hline
\end{tabular}

ment instituted. One drop of the test medication $(1.0 \%$ active drug or placebo) was applied to the operative eye one hour prior to the laser procedure and immediately after it. The ocular examination and heart rate and blood pressure measurements were repeated hourly during the first three hours after operation and again one week later. After the laser treatment the patients continued their usual ophthalmic medication, with the addition of betamethasone $0 \cdot 1 \%$ drops four times daily for four days. Additional antiglaucoma medication was administered as needed in those patients who had a rise of IOP.

The laser procedures were carried out as follows:

$N d-Y A G$ laser posterior capsulotomy. This was done under topical anaesthesia with the minimum energy settings and pulses required to create at least a $2 \mathrm{~mm}$ central opening in the posterior capsule. The eye was not dilated prior to treatment unless necessary. If the eye had to be dilated, the IOP was measured one hour after the dilatation and just prior to laser therapy.

Argon Nd-YAG iridotomy. This was done under topical anaesthesia. Argon laser (blue-green) was applied with a $50 \mu \mathrm{m}$ spot, $0 \cdot 2$ second duration, power 500 milliwatts. The laser pulses were focused at a peripheral superior nasal crypt if possible. The number of applications varied from 10 to 100 to stretch the iris and coagulate the vessels. The patient was then moved to the Coherent Nd-YAG laser 9900 . The previously treated site was focused with energy level of 4 to $6 \mathrm{~mJ}$ in one or two burst modes. A total of 5 to 200 applications were made to produce an adequate iridotomy. The patency was checked to ensure at least a $50 \mu \mathrm{m}$ opening. If the iridotomy closed in the follow-up period and the patient needed further laser treatment, he did not receive the test drug during this further procedure.

For the evaluation of the efficacy of the drug, the data from the two procedures were pooled. Data collected from this study was analysed as follows:

Demographic data for each treatment group were compared by two-way analysis of variance (ANOVA) for age and $\chi^{2}$ for sex, ophthalmological procedure, and ophthalmological diagnosis. A test of normal deviate was carried out on pretreatment intraocular pressures.

Analysis of data from patients with a significant rise in IOP, namely $10 \mathrm{~mm}$, or more than $10 \mathrm{~mm}$ from the baseline, or elevation $>40 \%$ of pretreatment IOP, was done by the $\chi^{2}$ test. The mean difference in the blood pressure and heart rate between the two groups was analysed by the paired $t$ test. For all analyses a $p$ value $>0.05$ was considered statistically significant.

\section{Results}

Demographic data from the 99 patients evaluated in this study are shown in Table 1 . There were no statistically significant differences $(p>0 \cdot 05)$ between treatment groups by age (Table 1), sex (Table 1), or in the mean baseline intraocular pressure (Table 2). Seventy patients underwent the laser iridotomy procedure and 29 required laser capsulotomy (Table $3)$. The lens status of patients enrolled for laser capsulotomy is given in Table 4 , showing similar distributions between treatment groups $(p>0 \cdot 05)$.

Table 2 Pretreatment IOP

\begin{tabular}{lccc}
\hline IOP in mm Hg & $\begin{array}{l}\text { Group l } \\
\text { (Apraclonidine) }\end{array}$ & $\begin{array}{l}\text { Group 2 } \\
\text { (placebo) }\end{array}$ & Total \\
\hline$<10$ & 7 & 4 & 11 \\
$10-15$ & 30 & 29 & 59 \\
$16-20$ & 8 & 13 & 21 \\
$21-25$ & 2 & 3 & 5 \\
$26-30$ & 1 & 1 & 2 \\
$>30$ & 0 & 1 & 1 \\
Total patients & 48 & 51 & 99 \\
\hline
\end{tabular}

Table 3 Laser procedures performed

\begin{tabular}{llll}
\hline & $\begin{array}{l}\text { Group 1 } \\
\text { (Apraclonidine) }\end{array}$ & $\begin{array}{l}\text { Group 2 } \\
\text { (placebo) }\end{array}$ & Total \\
\hline Capsulotomy & 17 & 12 & 29 \\
Iridotomy & 31 & 39 & 70 \\
Total patients & 48 & 51 & 99 \\
\hline
\end{tabular}


Table 4 Features in patients who underwent capsulotomy

\begin{tabular}{llll}
\hline & $\begin{array}{l}\text { Group I } \\
\text { (Apraclonidine) }\end{array}$ & $\begin{array}{l}\text { Group 2 } \\
\text { (placebo) }\end{array}$ & Total \\
\hline Aphakic & 12 & 7 & 19 \\
PC IOL & 4 & 4 & 8 \\
AC IOL & 1 & 0 & 1 \\
Iris clip IOL & 0 & 1 & 1 \\
Total patients & 17 & 12 & 29 \\
\hline
\end{tabular}

$\mathrm{PC}=$ posterior chamber. $\mathrm{AC}=$ anterior chamber. $\mathrm{IOL}=$ intraocular lens.

Table 5 Indications for iridotomy

\begin{tabular}{lllc}
\hline & $\begin{array}{l}\text { Group I } \\
\text { (Apraclonidine) }\end{array}$ & $\begin{array}{l}\text { Group 2 } \\
\text { (placebo) }\end{array}$ & Total \\
\hline $\begin{array}{l}\text { Chronic angle } \\
\quad \text { closure }\end{array}$ & 16 & 31 & 47 \\
$\begin{array}{l}\text { Fellow eye } \\
\begin{array}{l}\text { Pupil block: other } \\
\text { causes }\end{array}\end{array}$ & 3 & 7 & 19 \\
Total patients & 31 & 1 & 4 \\
\hline
\end{tabular}

The majority of patients requiring laser iridotomy presented with chronic angle closure glaucoma (Table 5) with the overall distribution of patients between treatment groups being statistically similar $(\mathrm{p}>0 \cdot 05)$.

\section{EFFECTS ON POSTLASER IOP}

Although the baseline IOP was not statistically different between treatment groups (Table 2), the mean IOP decreased with apraclonidine treatment and increased with placebo treatment during the three hours following laser therapy (Fig. 1; $>>0.05$ ). The distribution of IOP changes from the prelaser baseline are shown in Table 6. The mean IOP after laser treatment was generally decreased with apraclonidine and increased with placebo

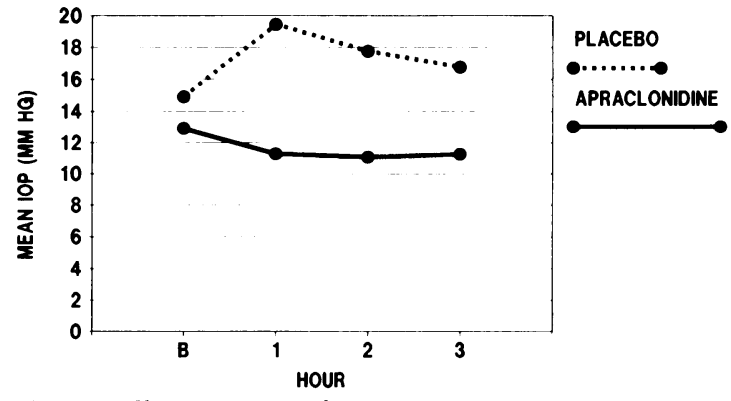

Fig. 1 Effect on intraocular pressure.

$(p<0 \cdot 05)$. Significant severe elevations in IOP following laser treatment (that is, IOP spike equal to or greater than $10 \mathrm{~mm} \mathrm{Hg}$ above the pretreatment baseline or greater than $40 \%$ above the pretreatment baseline) occurred in $52 \%(27 / 51)$ of patients in the placebo group and in $10 \%(5 / 48)$ of patients in the apraclonidine group (Table $7 ; \mathrm{p}<0 \cdot 05$ ). At one week after laser therapy the IOP was not statistically different between treatment groups.

EFFECTS ON CARDIOVASCULAR PARAMETERS Clinically significant effects on heart rate or blood pressure were not observed in patients from either treatment group at any time. In the three hours following laser treatment, however, some statistically significant findings unrelated to treatment were observed. The mean heart rate (Fig. 2) and systolic blood pressure (Fig. 3) were both statistically decreased from the prelaser baseline in both treatment groups $(\mathrm{p}<0 \cdot 05)$. Statistical changes in diastolic blood pressure were not found (Fig. 3).

\section{Discussion}

These results confirm other preliminary reports which

Table 6 IOP changes after laser treatment

\begin{tabular}{|c|c|c|c|c|c|c|}
\hline \multirow[t]{2}{*}{ Pressure changes in $\mathrm{mm} \mathrm{Hg}$} & \multicolumn{3}{|c|}{ Group I (Apraclonidine) } & \multicolumn{3}{|c|}{ Group 2 (Placebo) } \\
\hline & I Hour & 2 Hours & 3 Hours & 1 Hour & 2 Hours & 3 Hours \\
\hline \multicolumn{7}{|l|}{ Pressure elevation } \\
\hline $1-4$ & 8 & 4 & 9 & 8 & 16 & 17 \\
\hline $5-9$ & 5 & 4 & 3 & 13 & 10 & 10 \\
\hline $10-13$ & 0 & 1 & 2 & 10 & 3 & 2 \\
\hline$>14$ & 0 & () & 0 & 4 & 3 & 2 \\
\hline \multicolumn{7}{|l|}{ Pressure decrease } \\
\hline $1-4$ & 25 & 23 & 21 & 9 & 10 & 10 \\
\hline $5-9$ & 6 & 8 & 6 & 3 & 3 & 2 \\
\hline $10-14$ & 0 & 1 & 2 & $\ddot{1}$ & 2 & 2 \\
\hline $15-16$ & 1 & 0 & () & 0 & 0 & 1 \\
\hline$>17$ & 0 & 1 & 1 & 1 & 1 & 1 \\
\hline No change & 3 & 6 & 4 & 2 & 3 & 4 \\
\hline
\end{tabular}


Table 7 Significant IOP increase after laser treatment

\begin{tabular}{|c|c|c|c|}
\hline Procedure & Amount of increa & $\begin{array}{l}\text { e Group I } \\
\text { (Apraclonidine) }\end{array}$ & $\begin{array}{l}\text { Group 2 } \\
\text { (placeho) }\end{array}$ \\
\hline \multirow[t]{2}{*}{ Capsulotomy } & $\begin{array}{l}\geqslant 10 \mathrm{~mm} \text { above } \\
\text { baseline }\end{array}$ & 1 & 3 \\
\hline & $\begin{array}{c}>40 \% \text { above } \\
\text { baseline }\end{array}$ & 1 & 1 \\
\hline \multirow[t]{2}{*}{$\begin{array}{l}\text { Argon-YAG } \\
\text { Iridotomy }\end{array}$} & $\begin{array}{l}\geqslant 10 \mathrm{~mm} \text { above } \\
\text { baseline }\end{array}$ & 1 & 14 \\
\hline & $\begin{array}{c}>40 \% \text { above } \\
\text { baseline }\end{array}$ & 2 & 9 \\
\hline Total patients & & 5 & 27 \\
\hline
\end{tabular}

describe the effectiveness of apraclonidine in controlling postlaser IOP rises after laser trabeculoplasty, laser iridotomy and laser capsulotomy procedure. ${ }^{y-12}$ Unique to our study are the inclusion of patients with chronic closed-angle glaucoma and the combined use of the argon and Nd-YAG lasers to create iridotomies. Patients with chronic angle closure glaucoma had partial closure of the angle, and the iridotomy was done to prevent total closure of the angle. The use of both the argon and Nd-YAG lasers helped us to create iridotomies in the dark brown and thick irides seen in Indians. Our initial problems of not being able to create an adequate iridotomy with argon laser alone and the frequency of bleeds with the Nd-YAG alone have been overcome by this combined technique. Significant IOP elevation following anterior segment laser surgery can cause loss of fixation in patients with advanced glaucoma.'

Results from the short-term evaluation of apraclonidine provide evidence supporting the efficacy of this drug in preventing a rise of IOP after anterior segment laser procedure. No adverse experiences were noted in any patient throughout the course of the trial which could be attributed to the study drug; clinically significant differences in the heart rate measurements between the two groups were not observed. Thus topically administered apraclonidine appears to influence anterior chamber dynamics with minimal systemic effects. ${ }^{13}$ Further

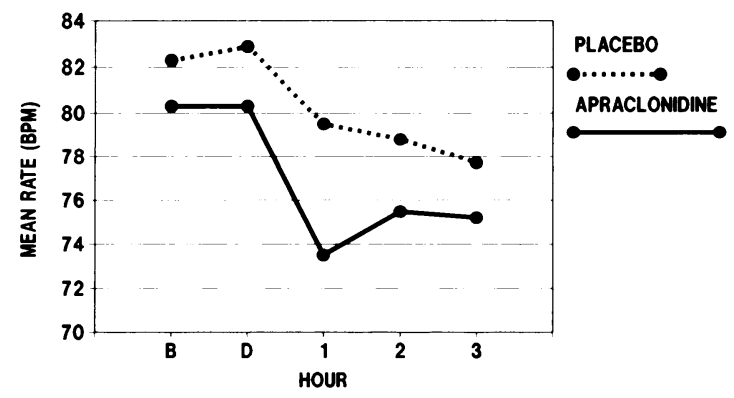

Fig. 2 Effect on heart rate.

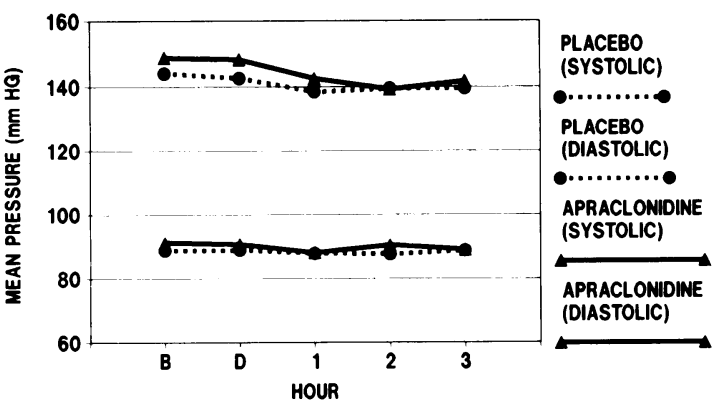

Fig. 3 Effect on blood pressure.

studies must be done to evaluate it as a topical antiglaucoma medication for more prolonged use.

The authors thank Alcon Laboratories for supplying the drug for evaluation. They also thank the Computer Department and Mr S Elumalai, biostatistician, for their help in the analysis of data; and Dr Al Reaves, for his technical support and review. The authors have no proprietary interest in Alcon Laboratories or Apraclonidine.

\section{References}

1 Weinreb RN. Ruderman J, Juster R, Sweig K. Immediate intraocular pressure response to argon laser trabeculoplasty. $\mathrm{Am}$ J Ophthalmol 1983: 95: 279-86.

2 Robin AL, Pollack IP. A comparison of Nd:YAG and argon laser iridotomies. Ophthalmology 1984; 91: 1011-6.

3 Henry KC, Krupin T, Schultz J, Wax M. Increased intraocular pressure following neodymium-YAG laser iridectomy. Arch Ophthalmol 1986: 104: 178.

4 Schrems W, Eichelbronner O, Kreigelstein GK. The immediate IOP response of $\mathrm{Nd}$ :YAG laser iridotomy and its prophylactic treatability. Acta Ophthalmol Khh 1984; 62: 673-80.

5 Flohr M, Robin AL. Kelley JS. Early complications following Qswitched Nd:YAG laser posterior capsulotomies. Ophthalmology 1985; 92: 360-3.

6 Terry AC, Stark WJ, Maumenee AE. Neodymium-YAG laser for posterior capsulotomy. Am J Ophthalmol 1983: 96: 716-20.

7 Hotchkiss ML, Robin AL, Pollack IP, Quigley HA. Nonsteroidal anti-inflammatory agents after argon laser trabeculoplasty. Ophthalmology 1984; 91: 969-74.

8 Roust B, Snyder $\mathrm{SH}$. $(3 \mathrm{H})$ para-aminoclonidine: a novel ligand which binds with high affinity to alpha-adrenergic receptors. Life Sci 1979; 25: 769-74.

9 Robin AL, Pollack IP, House B, Enger C. Effects of AL(2145 on intraocular pressure following argon laser trabeculoplasty. Arch Ophthalmol 1987; 105: 646-50.

10 Robin AL, Pollack IP, DeFaller JM. Effects of topical AL02145 on the acute intraocular pressure rise after argon laser iridotomy. Arch Ophthalmol 1987: 105: 1208-11.

11 Brown RH. Stewart RH, Lunch MG, et al. AL02145 reduces the intraocular pressure elevation following anterior segment laser surgery. Ophthalmology 1988: 95: 378-84.

12 Pollack IP, Brown RH, Crandall AS, Robin AL, Stewart RH, White GL. Prevention of the rise in intraocular pressure following neodymium-YAG posterior capsulotomy using topical 1\% apraclonidine. Arch Ophthalmol 1988: 106: 754-7.

13 Gharagozloo NZ, Relf SJ, Brubaker RF. Aqueous flow is reduced by alpha adrenergic agonist apraclonidine hydrochloride (AL02145). Ophthalmology 1988; 95: 1217-20. 